\title{
Transport and Environment Database System (TRENDS): Maritime Air Pollutant Emission Modelling
}

\author{
Georgakaki, Aliki; Coffey, Robert; Lock, Grahm; Sorenson, Spencer C
}

Published in:

Atmospheric Environment

Link to article, DOI:

10.1016/j.atmosenv.2004.07.038

Publication date:

2005

Document Version

Publisher's PDF, also known as Version of record

Link back to DTU Orbit

Citation (APA):

Georgakaki, A., Coffey, R., Lock, G., \& Sorenson, S. C. (2005). Transport and Environment Database System (TRENDS): Maritime Air Pollutant Emission Modelling. Atmospheric Environment, 39(13), 2357-2365. https://doi.org/10.1016/j.atmosenv.2004.07.038

\section{General rights}

Copyright and moral rights for the publications made accessible in the public portal are retained by the authors and/or other copyright owners and it is a condition of accessing publications that users recognise and abide by the legal requirements associated with these rights.

- Users may download and print one copy of any publication from the public portal for the purpose of private study or research.

- You may not further distribute the material or use it for any profit-making activity or commercial gain

- You may freely distribute the URL identifying the publication in the public portal 


\title{
Transport and Environment Database System (TRENDS): Maritime air pollutant emission modelling
}

\author{
Aliki Georgakaki ${ }^{\mathrm{a}}$, Robert A. Coffey ${ }^{\mathrm{a}, 1}$, Graham Lock ${ }^{\mathrm{b}}$, Spencer C. Sorenson ${ }^{\mathrm{a}, *}$ \\ ${ }^{a}$ Section for Energy Engineering, Department of Mechanical Engineering, Technical University of Denmark (DTU), \\ Building 403, 2800 Kgs. Lyngby, Denmark \\ ${ }^{\mathrm{b}}$ European Commission, Office BECH B4/459, L-2920 Luxembourg/Kirchberg, Luxembourg
}

Received 19 January 2004; received in revised form 1 July 2004; accepted 12 July 2004

\begin{abstract}
This paper reports the development of the maritime module within the framework of the Transport and Environment Database System (TRENDS) project. A detailed database has been constructed for the calculation of energy consumption and air pollutant emissions. Based on an in-house database of commercial vessels kept at the Technical University of Denmark, relationships between the fuel consumption and size of different vessels have been developed, taking into account the fleet's age and service speed. The technical assumptions and factors incorporated in the database are presented, including changes from findings reported in Methodologies for Estimating air pollutant Emissions from Transport (MEET). The database operates on statistical data provided by Eurostat, which describe vessel and freight movements from and towards EU 15 major ports. Data are at port to Maritime Coastal Area (MCA) level, so a bottom-up approach is used. A port to MCA distance database has also been constructed for the purpose of the study. This was the first attempt to use Eurostat maritime statistics for emission modelling; and the problems encountered, since the statistical data collection was not undertaken with a view to this purpose, are mentioned. Examples of the results obtained by the database are presented. These include detailed air pollutant emission calculations for bulk carriers entering the port of Helsinki, as an example of the database operation, and aggregate results for different types of movements for France. Overall estimates of $\mathrm{SO}_{x}$ and $\mathrm{NO}_{x}$ emission caused by shipping traffic between the EU 15 countries are in the area of 1 and 1.5 million tonnes, respectively.
\end{abstract}

(C) 2005 Published by Elsevier Ltd.

Keywords: Maritime transport; Air pollutant emissions

\section{Introduction}

The TRENDS study of maritime shipping has aimed to estimate the environmental pressures caused by the

\footnotetext{
*Corresponding author. Tel.: + 4545254170 ; fax: +4545930663 .

E-mail address: scs@mek.dtu.dk (S.C. Sorenson).

${ }^{1}$ Current address: Skt.Annae Gade 33, 1 tv, 1416 Copenhagen $\mathrm{K}$, Denmark.
}

cruising activities of the world's commercial shipping fleet attending EU15 countries. The study estimates emissions occurring during cruising from shipping movements calling into ports of the EU15 countries, which involve the delivery or receipt of goods. Other related activities such as loading, hotelling, etc. are not examined at this point, but are under consideration for following stages of the project. The reference year for all transport modes examined by TRENDS was set to 1995 . However, detailed data referring to this year were not 
available for maritime traffic. The data sets so far included in the database cover the years 1997-2000, but are not complete. The best data set, for the year 2000, includes all EU15 member states except for Italy. Future datasets are to be added when available.

\section{Method}

The fleet is divided into different categories, which demonstrate similar characteristics in terms of operation, goods carried, physical proportions and auxiliary machinery. The categories used are as defined in Lloyd's Register of Ships. Gross tonnage (GT) is chosen as the measure of a ship's size. However, links are also developed between the deadweight and GT of different types of ships, so these figures are interchangeable. The ship categories and respective relationships between GT and deadweight can be observed in Table 1. The relationship is very strong for tankers, bulk carriers, general cargo and container vessels, while for Roll on/ Roll off (RoRo) and passenger ships there is more variability, as can be seen from the $R$-squared deviation given in the same table. This may be attributed to the varied use of space on such ships. Often RoRo vessels carry passengers, and passenger vessels carry vehicles and cargo. The factors are based upon an in-house ship database, created and maintained at DTU in the Department of Naval Architecture and Offshore Engineering. The database contained around 2300 entries.

A second division is made based on propulsion machinery, as medium speed engines are found in smaller ships and slow speed engines in larger vessels. Although there is no definite size boundary that divides the engine types, several studies have indicated suitable assumptions, such as $2500 \mathrm{GT}$, Flodström (1997), and $2000 \mathrm{~kW}$, Lloyd's Register Engineering Services (1995). Engines below this size are assumed to be medium speed and engines above this size are assumed to be slow speed.

A one-to-one relationship exists between average GT and installed power $(\mathrm{kW})$ for ships within this range, and therefore, within the TRENDS project, it is assumed that all ships under $2000 \mathrm{GT}$ have medium speed and those over 2000 GT have slow speed engines. It is also assumed that slow speed engines run on marine fuel oil (energy content $40.0-40.5 \mathrm{MJ} \mathrm{kg}^{-1}$ ), while medium speed engines run on marine gas oil (energy content $42.0-42.5 \mathrm{MJ} \mathrm{kg}^{-1}$ ).

\subsection{Energy consumption}

The specific fuel consumption (SFC) of the marine diesel engine has decreased rapidly over the past 30 years. The SFC of a modern diesel engine can be $160 \mathrm{~g} \mathrm{kWh}^{-1}$ compared to $220 \mathrm{~g} \mathrm{kWh}^{-1}$ for an older engine. The steam turbine on the contrary, which has not undergone the same development, offers a SFC of around $280 \mathrm{~g} \mathrm{kWh}^{-1}$ (Hughes, 1996).

The age distribution of 290 ships of different types, randomly chosen from the Lloyd's Register of Shipping, 1994-1995 was examined to provide an indication of the age of ships operating during the study period. The majority of ships were introduced to the fleet between 1970 and 1995, although significant numbers were introduced before 1970, which illustrates their relatively long working lives. The average launch date was 1987. This date varied for different types of ships. General cargo ships had an ageing population and container ships a young population as may be expected from the current trend towards container use. The weighted average SFC was calculated based upon slow speed engine test bed data and the age distribution. It was approximated at $187 \mathrm{~g} \mathrm{kWh}^{-1}$. A SFC of $200 \mathrm{~g} \mathrm{kWh}^{-1}$ was used in the studies; Bouscaren (1990), Alexandersson et al. (1993) and Flodström (1997). Although not explicitly stated in the report by Lloyd's Register Engineering Services (1995), carbon or sulphur balancing of the emission factors gave a SFC of $210 \mathrm{~g} \mathrm{kWh}^{-1}$. Considering that about $30 \%$ of the fleet runs on less efficient four-stroke and steam turbine engines, and that the data used represented the engines running under ideal operating conditions on a test bed, an average SFC of $205 \mathrm{~g} \mathrm{kWh}^{-1}$ is adopted in this study in order to compensate for these facts and also for the existence of ageing engines in the fleet. This consumption is used with all engines, irrespective of engine load or age. It is also assumed that the main engine and auxiliary load

Table 1

Relationship between dead weight and fuel consumption with gross tonnage

\begin{tabular}{lllll}
\hline Vessel type & Dead weight (tonnes) & $R$-squared deviation & Fuel consumption $\left(\mathrm{kg} \mathrm{km}^{-1}\right)$ & $R$-squared deviation \\
\hline Tanker & $1.87 \times \mathrm{GT}$ & 0.9886 & $0.2283 \times \mathrm{GT}^{0.5589}$ & 0.8865 \\
Bulk carrier & $1.83 \times \mathrm{GT}$ & 0.9859 & $0.3059 \times \mathrm{GT}^{0.5241}$ & 0.913 \\
General cargo & $1.39 \times \mathrm{GT}$ & 0.9287 & $0.1637 \times \mathrm{GT}^{0.6024}$ & 0.7105 \\
Container & $1.09 \times \mathrm{GT}$ & 0.9445 & $0.0489 \times \mathrm{GT}^{0.7381}$ & 0.7748 \\
RoRo/ferry/cargo & $0.54 \times \mathrm{GT}$ & 0.5404 & $1.2324 \times \mathrm{GT}^{0.3967}$ & 0.3025 \\
Passenger ship & $0.18 \times \mathrm{GT}$ & 0.7816 & $0.173 \times \mathrm{GT}^{0.6134}$ & 0.7509 \\
\hline
\end{tabular}


generate a combined output equivalent to $85 \%$ of the main engine capacity. Of this, $5 \%$ accounts for auxiliary engine operation. This assumption is based on bibliography information on the size of the auxiliary engine with regards to the main engine $(20-30 \%)$ and the average load of auxiliary engines under cruising conditions (Flodström, 1997). It is also assumed that the auxiliary engine consumes gas oil.

From the assumptions described previously, the fuel consumption (FC) factors per kilometre seen in Table 1 are derived for the different ship categories using the inhouse DTU database. The factors of FC per unit distance include the influence of the speed of the vessel. The speed of ships tends to increase with size and this is taken into account when estimating the FC per unit distance. For this purpose the service speed is used, which is defined as, "that which the ship is stated to be capable of maintaining at sea in normal weather and at normal service draught'.

The FC factors have been compared with those produced by MEET (Trozzi and Vaccaro, 1998). A reasonable correlation is observed between the MEET and DTU factors as can be seen in Fig. 1(a), with the exception of bulk carriers. As shown in Fig. 1(b), the DTU estimates are significantly greater than those produced by MEET. The MEET factors assume a linear relationship between GT and FC, as well as an average speed for each category of vessel. A power curve is used to estimate the FC of the ships within the DTU database. This is considered to give a better representation of the relationship with GT, especially for the smaller vessels, as seen in Fig. 1(b).

\subsection{Emission factors}

The most extensive study into marine diesel engine emissions measurements has been performed by Lloyd's Register Engineering Services Ltd., Lloyds (1995). The Lloyd's emission factors for slow and medium speed marine diesel engines are adopted for this calculation, with the exception of particulate matter. The emission factors for steam turbine engines are quoted from the United States Environmental Protection Agency (1985). As the relevance of European refinery estimates was limited, this study has adopted the EMEP/CORINAIR (1996) guidebook recommended sulphur content figures. The sulphur content of fuel oils is therefore assumed to be $2.99 \%$ and that of gas oils $0.73 \%$. The user of the database can redefine this assumption. As no information was available for the power plant mixture of the ships attending different ports a weighted average is assumed, based on the survey by Lloyd's Register Engineering Services. In the study it was observed that around $71 \%$ of the installed main engine power was accounted for by slow speed engines, around $23 \%$ was found to be medium speed engines and $6 \%$ steam turbines. The balance between steam turbine engines, medium speed and slow speed diesel engines can also be modified by the user.

The particulate matter for the Lloyd's study was measured over just six engines, representing a range of marine vessel types. The emission factor does not take into account the effect of the fuel's sulphur content on particulate matter emission. Using the Lloyd's values as reference points, a correlation was developed to calculate the particulate matter emission as follows:

$$
\frac{\mathrm{PM}}{\mathrm{PM}_{\text {ref }}}=0.6\left(\frac{\mathrm{S}-S_{\text {ref }}}{S_{\text {ref }}}\right)+1 \text {. }
$$

$\mathrm{PM}_{\text {ref }}$ and $S_{\text {ref }}$ are the values given by Lloyd's, while $\mathrm{S}$ is the actual sulphur content of the fuel in question and PM the emission factor for this fuel. The correlation was developed using the relationships given by Wall and Hoekman (1984) with fuel characteristics particular to marine fuels. Table 2 displays the adopted emission factors along with the factors produced as a weighted average using all the assumptions mentioned.

\subsection{Input data}

Traffic statistics for all shipping movements involving EU15 countries are supplied by the European Commission Statistical Office. This information is made
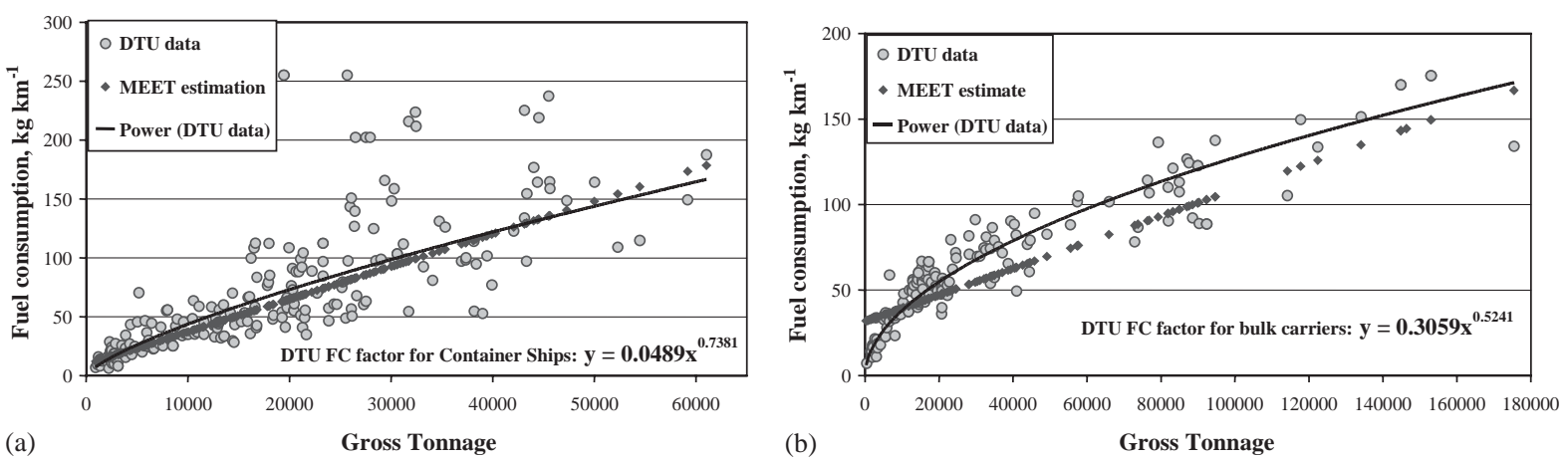

Fig. 1. FC correlation for container ships (a) and bulk carriers (b). 
Table 2

Emission factors ( $\mathrm{kg}$ tonne fuel $^{-1}$ ) used in the database

\begin{tabular}{|c|c|c|c|c|c|c|}
\hline & \multicolumn{2}{|l|}{ Lloyds } & \multicolumn{2}{|l|}{ US EPA } & \multicolumn{2}{|c|}{ TRENDS } \\
\hline & \multirow{2}{*}{$\frac{\text { Slow speed }}{\text { Fuel oil }}$} & \multirow{2}{*}{$\begin{array}{l}\text { Medium speed } \\
\text { Gas oil }\end{array}$} & \multicolumn{2}{|c|}{ Steam turbine } & \multicolumn{2}{|l|}{ Average } \\
\hline & & & Fuel oil & Gas oil & Fuel oil & Gas oil \\
\hline $\mathrm{NO}_{x}$ & 87 & 57 & 6.98 & 6.25 & 81.4 & 54.97 \\
\hline $\mathrm{CO}$ & 7.4 & 7.4 & 0.43 & 0.6 & 6.91 & 7.13 \\
\hline $\mathrm{HC}$ & 2.4 & 2.4 & 0.085 & 0.5 & 2.24 & 2.32 \\
\hline $\mathrm{CO}_{2}$ & 3170 & 3170 & 3170 & 3170 & 3170 & 3170 \\
\hline $\mathrm{SO}_{2}$ & $20 \times \% \mathrm{~S}$ & $20 \times \% \mathrm{~S}$ & $20 \times \% \mathrm{~S}$ & $20 \times \% \mathrm{~S}$ & 59.8 & 14.6 \\
\hline PM & 7.6 & 1.2 & 2.5 & 2.08 & 7.7 & 1.55 \\
\hline
\end{tabular}

Source: Lloyd's Register Engineering Services Ltd. and US Environmental Protection Agency.

available by the member states in accordance with the Council Directive 95/64/EC and 98/358/EC. Data sets A1, A2, F1, F2 and D1 as defined by the directive provide the database input. Due to the sensitivity of the data for port competition, dissemination is at this point only possible at a port-to-MCA level and not port-toport as was originally intended. This restriction causes complications in estimating the distance travelled by vessels, as certain MCAs cover a rather long coastline. The calculations are based on a Port-to-MCA distance table, which was provided by Eurostat.

Two tables in each data set record the movement of goods between ports and maritime coastal areas, namely, Tables A1 and A2. While data set A2 has a more detailed account of the cargo carried, it does not register all types of freight so extracts from both tables are used in the calculation procedure. These data include the reporting port, the maritime coastal area of the origin or destination port, the cargo type and mass.

Shipping movements by vessel type are recorded in data set F2. The data are specific to each port and give information about the arriving vessels. They do not give the origin or destination MCA of the journey. The data indicate the tonnage category, number of vessels and GT of the vessels. The vessel types described in the directive are not the same as the categories defined by the study and therefore a correlation is used, as shown in Table 3.

The goods traffic data register the amount of each type of cargo arriving and leaving each port, and the origin or destination of the goods. The vessel data describe the number and size of vessels arriving at each port, but does not state the origin or destination MCA. As a result, while FC factors can be calculated for each port according to the type and size distribution of vessels calling, the total estimate of FC and consequently, the emissions occurring has to be based on the goods traffic, which provides information on the total distance sailed. For this reason, the relationship between the goods transported and the different carriers has to be established.
Eurostat registers five main types of cargo: liquid bulk, dry bulk, containers, RoRo and other (not specified) cargo. The number of passengers is also registered. Problems are encountered mainly with attributing passengers and RoRo cargo. Table 3 shows that passengers may be allocated to general cargo (by Eurostat definition) vessels or to passenger vessels, or split between the two. The passengers are all attributed to passenger ships, in absence of a way to distinguish between RoRos that may carry them. This allocation process creates problems. It is observed that passenger vessels produce occupancies that are not realistic by an order of magnitude or more, while RoRo vessels seem to consistently carry very small loads. The explanation for this is obvious; the fact that passengers are carried in RoRo vessels is not accounted for, nor is the weight from such activities, including the weight of passenger vehicles, lorries, etc. Note that the weight of vehicles carrying cargo is also not included by the directive. There is also a suspicion that goods travelling in RoRo vessels are registered according to their nature (e.g. dry bulk goods in lorries, containers) and then falsely attributed to other types of carriers. Further research into these issues and recommendations for solutions are provided by Georgakaki and Sorenson (2002).

The above-mentioned problems are inherent in the way the data are recorded, and while it depreciates any factors produced per unit of cargo or passenger carried for the time being, it should not influence the resulting emissions, assuming that there is consistency in the registration.

\subsection{Port to MCA distance database}

An estimation of the sailing distances was provided by Eurostat, in order to relate the origin and destination port and MCA descriptions to actual distances. The Veson Distance Tables from Fairplay were used to look up sailing distances. For missing ports an estimate was 
Table 3

Eurostat definition of ship types and correlation with the TRENDS categories

\begin{tabular}{|c|c|c|}
\hline Eurostat & Ship categories included by Eurostat & TRENDS \\
\hline Liquid bulk & Oil tanker, chemical tanker, LG tanker, tanker barge, other tanker & Tanker \\
\hline Dry bulk & Bulk/oil carrier, bulk carrier & Bulk carrier \\
\hline Container & Full container & Container ship \\
\hline Specialised & $\begin{array}{l}\text { Barge carrier, chemical carrier, irradiated fuel, livestock carrier, vehicle } \\
\text { carrier, other specialised }\end{array}$ & General cargo \\
\hline $\begin{array}{l}\text { General cargo, non } \\
\text { specialised }\end{array}$ & $\begin{array}{l}\text { Reefer, RoRo passenger, RoRo container, other RoRo cargo, } \\
\text { combination carrier general cargo/passenger, combination carrier general } \\
\text { cargo/cargo, single-decker, multi-decker }\end{array}$ & RoRo/ferry/cargo \\
\hline Dry cargo barge & $\begin{array}{l}\text { Deck barge, hopper barge, lash-seabee barge, open dry cargo barge, } \\
\text { covered dry cargo barge, other dry cargo barge }\end{array}$ & Bulk carrier \\
\hline Passenger & Cruise, other passenger only & Passenger ship \\
\hline
\end{tabular}

made based on neighbours along the same coastline and then the distances were adjusted on the basis of the unknown port's co-ordinates. In the majority of cases it was considered sufficient to take the shortest route. Only the most important inland ports were considered by calculating distances along the rivers or canals to a port at the mouth of the river, and then sea distances from there. It was decided not to estimate the average effect of weather. Up to date data were extracted on a port-toMCA basis (11950 pairs). The major ports for each MCA within the EU were identified from the raw data, covering at least $70 \%$ of the throughput for that MCA. For overseas MCAs, only one or two major ports were used. The results cover about $95 \%$ of the port-MCA pairs. In most cases, the missing records lack information on the partner MCA or refer to non-port locations. However, more than a third of the missing records are due to a lack of information on the location of minor Greek ports. Small numbers of minor ports from other countries could also not be located.

Port-MCA distances are inherently less precise than port-port distances, due to information lost in aggregation. This is especially true for ferries and bulk trades. It would be advisable to develop separate distance tables for different commodity groups and for passengers. The port-port flows of goods and passengers do not provide information on the route. A flow between two ports may involve a vessel calling at other ports along the way. There is thus an in-built underestimation of the real distance. This situation can only be rectified by collecting data on vessel movements, which include information on all ports of call for a particular journey.

\subsection{Allocation of environmental indicators}

There are different options for the allocation of emissions from maritime activities. Ideally, the environmental responsibility needs to be placed with those parties, which are directly gaining from the activity. This is not a straightforward decision because the beneficiaries are diverse and are distributed between different countries. In terms of the TRENDS project, the allocation of environmental indicators also needed to consider the available data.

Ownership and registration of a vessel can be fragmented and lie with several different countries. Emissions could be assigned to these countries, as some level of financial benefit is being derived there. The statistical traffic data available to TRENDS, included adequate data to provide for such an allocation, however, this would not indicate where the emissions were produced.

The supply of marine fuels could be used as a measure of the maritime activity associated with each country. Although there is some physical link between the emissions and the country of bunker sales, the majority of airborne emissions may be discharged far from this country. Furthermore, the fact that fuel has been acquired from a country does not necessarily mean that the country will be receiving any other benefit from the shipping activity. Also, bunker fuel statistics are rather uncertain for most ports, resulting in discrepancies between bunker fuel sales and actual fuel usage, as also reported by Koehler (2003).

Different sea areas may be treated as individual sections to which emissions are allocated. This is a good method of estimating emissions in a geographically representative manner. However, placing responsibility for these emissions may be difficult.

The need for shipping is generated by the requirement for the import and export of goods. The allocation of environmental indicators to the importing or exporting countries is therefore well justified; especially if the allocation is made on the basis of transported goods. The traffic data available to the TRENDS permits allocation of emissions by this principle. The responsibility for each route was divided equally between the origin and destination ports. This provides a link between the country of allocation and the geographic location of 
the emissions discharged. Even though the majority of emissions may be generated away from either the country of origin or destination, the emissions can be allocated to each route. This gives the possibility of future enhancement using GIS to provide emissions estimates distributed along the European shipping routes.

The method loses some substance in particular cases. For example, if a ship makes a long haul and then delivers to a cluster of several closely distributed ports, the emissions allocation to the first port of call will be higher than that of the following ports for the same delivery of goods. This may also be observed when goods are delivered to a central port such as Rotterdam, only to be dispersed to smaller ports in neighbouring countries. Rotterdam will be receiving little financial benefits, but possibly a large allocation of emissions.

\subsection{Fuel consumption calculation method for freight vessels}

The following describes the calculation of the FC to be allocated to each port. This applies to all cargo vessels and RoRo ferries but not to passenger vessels for which a respective calculation method has been developed, attributing passengers instead of cargo.

Step 1: The FC relationships for each type of vessel, as described in Table 1, are applied to each size class of the vessels arriving at each port, based on the average GT calculated. This provides a FC for the average vessel of each type and size class for the particular port, as shown in Table 4 for bulk carriers calling at Helsinki.

Step 2: A weighted average SFC is calculated for each vessel type based on the size distribution of ships attending each port and the total GT available in each class, as shown in Table 4.

Step 3: The aggregated FC per kilometre is calculated for the fleet of each vessel type attending each port, as shown in Table 4. Data are not available detailing the sizes of vessels taking particular trips, so it is assumed that the same distribution of different sized vessels operates over each route.

Step 4: The aggregated FC for each vessel type is divided by the aggregated quantity of goods entering/ leaving each port to calculate the average SFC per incoming/outgoing tonne of goods transported $1 \mathrm{~km}$, as shown in Table 5.

Step 5: The ton $\mathrm{km}$ of incoming and outgoing goods transported over each route is calculated. The maritime distance of each route is obtained from the port to MCA database. This distance is divided by two, as only half of the route is allocated to the reporting port.

Step 6: From the SFC calculated for incoming and outgoing vessels and the respective goods traffic data the fuel consumed over a particular route in a given time period is produced.

\subsection{Emissions estimation method}

The following section describes the calculation of the emissions to be allocated to each port.

Step 1: The FC of vessels under $2000 \mathrm{GT}$ is calculated.

Step 2: The average fraction of gas oil used by each type of ship at each port is calculated. This includes the FC of vessels under $2000 \mathrm{GT}$ and the $5 \%$ used by auxiliary engines.

Step 3: The total FC is split into gas and fuel oil components.

Step 4: Emission factors are applied to the gas and fuel oil components to obtain the total emissions from each route that should be allocated to each reporting port.

Except for the total emission allocated to each port, subtotals may be calculated for emissions occurring due to short sea shipping (SSS), deep sea shipping (DSS), national or European (EU) destinations, as seen in Table 6. The MCA relative for each type of activity can be defined by the user for each country. The definition used in the database at the moment is provided by Eurostat.

Table 4

Calculation of fuel consumption per kilometre for bulk carriers entering the port of Helsinki by tonnage range. First quarter of 2000

Calculation of specific fuel consumption per $\mathrm{km}$ travelled by the fleet

\begin{tabular}{|c|c|c|c|c|c|c|c|}
\hline $\begin{array}{l}\text { Reporting } \\
\text { port }\end{array}$ & Tonnage range & $\begin{array}{l}\text { No. of } \\
\text { vessels }\end{array}$ & Total GT & $\begin{array}{l}\text { Average } \\
\text { GT }\end{array}$ & $\begin{array}{c}\text { Vessel FC } \\
\left(\mathrm{kg} \mathrm{km}^{-1}\right)\end{array}$ & $\begin{array}{l}\mathrm{SFC} \\
\left(\mathrm{g} \mathrm{GT}^{-}\right. \\
\left.\mathrm{km}^{-1}\right)\end{array}$ & $\begin{array}{l}\text { Fleet FC } \\
\left(\mathrm{kg} \mathrm{km}^{-1}\right)\end{array}$ \\
\hline Helsinki & Up to 499 & 25 & 4164 & 167 & 4.47 & 26.8 & 112 \\
\hline Helsinki & $1000-1999$ & 1 & 1102 & 1102 & 12.02 & 10.9 & 12 \\
\hline Helsinki & 2000-2999 & 1 & 2163 & 2163 & 17.12 & 7.91 & 17 \\
\hline Helsinki & $10,000-19,999$ & 4 & 50148 & 12,537 & 43.00 & 3.43 & 172 \\
\hline Helsinki & $20,000-29,999$ & 4 & 113,320 & 28,330 & 65.92 & 2.33 & 264 \\
\hline Total & All & 35 & 170,897 & & & & 577 \\
\hline Average & & & & 4883 & 16.47 & 3.37 & \\
\hline
\end{tabular}


Table 5

Specific fuel consumption of bulk carriers entering the port of Helsinki with respect to goods weight. quarterly results for the year 2000

Calculation of specific fuel consumption per tonne $\mathrm{km}$ of goods carried

\begin{tabular}{llllll}
\hline Reporting port & Reference & Cargo type & $\begin{array}{l}\text { Gross weight of } \\
\text { goods (tonnes) }\end{array}$ & $\begin{array}{l}\text { Fleet FC } \\
\left(\mathrm{kg} \mathrm{km}^{-1}\right)\end{array}$ & $\begin{array}{l}\text { SFC } \\
\left.(\mathrm{g} \mathrm{tonne} \mathrm{km})^{-1}\right)\end{array}$ \\
\hline Helsinki & Q1 & Dry bulk & 232,237 & 577 & 2.48 \\
Helsinki & Q2 & Dry bulk & 112,656 & 396 & 3.52 \\
Helsinki & Q3 & Dry bulk & 191,837 & 738 & 3.58 \\
Helsinki & Q4 & Dry bulk & 338,642 & 1140 & 3.37 \\
\hline
\end{tabular}

Table 6

Air pollutant emissions of dry bulk carriers calling in Finish ports for the year 2000 according to their destination (tonnes)

\begin{tabular}{|c|c|c|c|c|c|c|c|c|}
\hline \multicolumn{9}{|c|}{ Air pollutant emissions per area of activity } \\
\hline Country & Vessel type & Activity & $\mathrm{CO}_{2}$ & $\mathrm{SO}_{x}$ & $\mathrm{CO}$ & $\mathrm{HC}$ & PM & $\mathrm{NO}_{x}$ \\
\hline Finland & Dry bulk & EU & 104,000 & 1740 & 228 & 74 & 223 & 2540 \\
\hline Finland & Dry bulk & DSS & 161,000 & 2740 & 354 & 115 & 351 & 3970 \\
\hline Finland & Dry bulk & SSS & 40,700 & 696 & 89 & 29 & 89 & 1000 \\
\hline
\end{tabular}

\section{Results}

These results are shown as an example of the database capabilities, with certain reservations as to their accuracy, due to the problems encountered with the data. Note that SSS and EU destinations overlap in the graph, due to the present definition given by Eurostat. This is easily amended by the selection of different relevant MCAs by the user, and it is also taken into account when aggregated figures are quoted. Fig. 2 shows $\mathrm{SO}_{x}$ emission for France according to vessel type and destination. Container vessels are the greatest contributors, due to the long distance sailed, which is averaged around 4000 nautical miles, while the average load is calculated at approximately 7400 tonnes. However, container vessels only have a $12 \%$ share of the goods carried according to the present attribution. The largest portion goes to liquid bulk carriers, which share $49 \%$ of the tonnage. In terms of vessels calling in French ports, RoRos are predominant with a $67 \%$ share of the vessels. The average distance travelled at around 500 nautical miles and the average load attributed to them, of approximately 800 tonnes, is a lot smaller than that of container vessels, which mostly have overseas destinations, so their emission contribution is not as high.

A calculation of the emissions produced by cruising activities of shipping movements between the EU15 countries and also between the EU15 countries and accession states was performed through this database and compared relevant data produced by another study performed for the Commission (Entec Uk Limited, 2002). TRENDS estimates $\mathrm{SO}_{x}$ emission caused by cruising activities of shipping traffic between the EU15 countries to be in the area of 1 million tonnes, while for $\mathrm{NO}_{x}$ the estimate is approximately 1.5 million tonnes. For traffic between EU 15 and accession countries the estimates for $\mathrm{SO}_{x}$ and $\mathrm{NO}_{x}$ are just under 300 thousand tonnes and 400 thousand tonnes, respectively. In both cases results for $\mathrm{SO}_{x}$ and $\mathrm{NO}_{x}$ emissions calculated by the two studies agree within $20 \%$. Since the two studies are based on different data sources and also present differences in methodology this result is very encouraging, especially considering the data uncertainties involved in this project.

Further assessment of the accuracy of the TRENDS database is difficult to obtain, due to the lack of measurements or even scientific studies with the same scope. Other recent publications concerning maritime emissions, such as the ones by Corbett and Koehler (2003), Endresen et al. (2003), while relevant for the time frame in question, look at the marine emissions on a global scale and are not comparable to the results obtained here.

\section{Discussion}

Even though a quantification of the uncertainties is difficult to obtain, work with the database has revealed that results for movements within the EU 15 are unlikely 


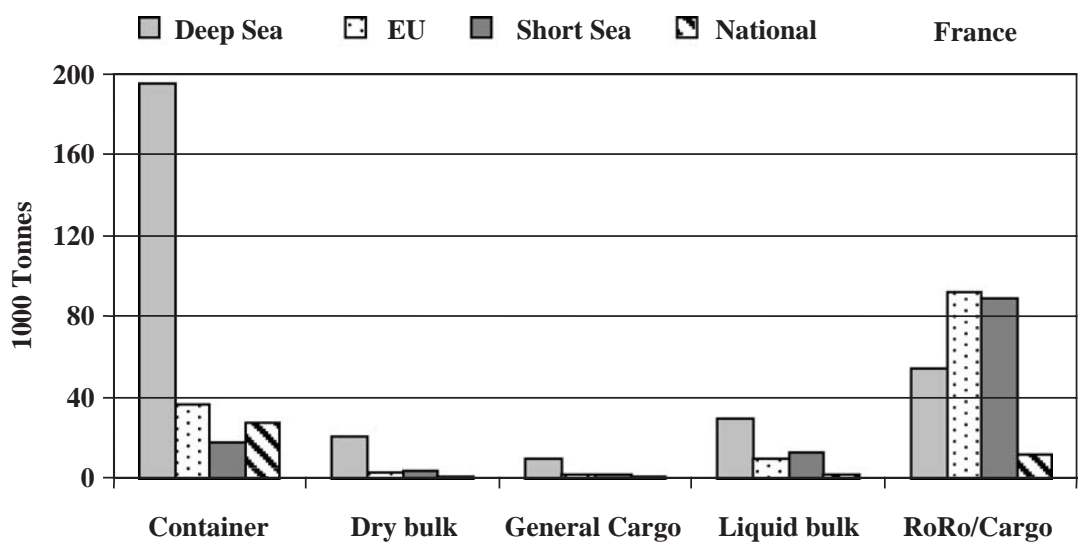

Fig. 2. $\mathrm{SO}_{x}$ emission for France (a) according to vessel type and destination for the year 2000.

to be influenced by the inaccuracy inherent in the Port to MCA distance system. This is to be expected as distances within the EU15 and the accession countries are shorter, and the MCAs better defined than for overseas transport. When it comes to ship types and their FC, RoRo vessels are the category for which the FC data present a wider distribution, making the correlation more uncertain than the ones developed for other vessels. The assumption that the same fleet operates over all routes may have the effect of underestimating FC for short journeys and increasing it for longer trips. This could happen for movements originating from major ports where both very large and smaller vessels call. It is unlikely that the large carriers will contribute to short trips, but this cannot be taken into account with the present data. Auxiliary engines of certain ship types, like refrigerated cargo vessels or passenger ships are known to run under higher average loads than the one assumed here. This is difficult to treat with the present data structure, however, as the increase in the percentage load of the main engine is a userdefined parameter, the option exists for individual calculations under different input conditions. The fact that raw statistical data are the input for TRENDS means that it is susceptible to errors caused by wrongly registered information. The quality of the statistics is controlled by Eurostat and there is an ongoing effort to increase the accuracy and consistency of the data. The following suggestions are a contribution to this effort and a guideline on how to assess and further improve the accuracy of the TRENDS database.

It is recommended that the actual tonnage of goods carried on a ship, regardless of the type of goods, be made available as a statistic. If, when vessel movement is registered the amount of cargo and the destination of the ship are recorded, then there is sufficient information to calculate the environmental indicators from the different types and sizes of ships.
Since most other groups work with the RoRo as a vessel type, it is strongly recommended that Eurostat adapt its definitions and data collection procedures to accommodate this type of ship. As a minimum, one class of vessel called a RoRo should be established. Consideration should be given to separate passenger and cargo RoRo, though it is recognized that there may be instances where these are mixed.

The use of different average MCA distance for passengers and goods should be considered.

It is recommended that an evaluation be performed to compare the results of environmental indicators obtained from using average MCA distances to those resulting from the use of actual port-to-port distances with a calculation performed on detailed confidential data. It is otherwise difficult to assess the error caused by this simplification, as traffic for each port is unique and therefore the assumption has a different impact. This appears to be possible only internally within Eurostat.

Finally, the TRENDS maritime database is designed as a tool open to the user, so that input data, such as the FC curves, emission factors, etc. could be modified to permit calculations for special areas or scenario cases. This will also allow suitable updating of factors to reflect changes within the fleet. Obviously, such changes would influence the overall performance of the database in a way that cannot be predicted, so the input parameters should always be clearly stated before reviewing results.

\section{Conclusion}

A methodology has been developed for the calculation of air pollutant emissions arising from cruising activities of maritime transport, utilising Eurostat maritime statistics. A detailed database providing results at port level for each vessel type has been constructed. Results can be obtained on an aggregate level for the 
whole EU or according to destination (DSS, SSS, EU, and National). The database is open to the user for modification of input parameters, which is important both for keeping the database up to date and examining different scenarios.

A more interdisciplinary approach is needed to tackle the problems encountered, assess and improve the accuracy of the database, and this will only be done effectively in close collaboration with Eurostat.

\section{Acknowledgments}

The TRENDS project was funded by the European Commission, DG VII/DG TREN.

\section{References}

Alexandersson, A., Flodstrom, E., Oberg, R., Stålberg, P., 1993. Exhaust Gas Emissions from Sea Transportation. Mariterm AB, Gothenburg, Sweden.

Bouscaren, R., 1990. Emissions of $\mathrm{SO}_{2}$ and $\mathrm{NO}_{x}$ in the British Channel by ship traffic. CITEPA, EMEP Workshop on Emissions from Ships Oslo, Norway 7-8 June 1990, pp. 14-21.

Corbett, J.J., Koehler, H.W., 2003. Updated emissions from ocean shipping. Journal of Geophysical Research-Atmospheres 108 (D20), 4650-4666.

Entec Uk Limited, 2002. Quantification of emissions from ships associated with ship movements between ports in the European Community. Study for the European Commission. Entec Uk Limited, Northwich, Cheshire, England, UK.

European Commission, 1995. Council directive 95/64/EC on statistical returns in respect of carriage of goods and passengers by sea. Official Journal of the European Communities.

European Commission, 1998. Council directive 98/385/EC on rules for implementing council directive 95/64/EC on statistical returns in respect of carriage of goods and passengers by sea. Official Journal of the European Communities.
EMEP/CORINAIR, 1996. Atmospheric Emission Inventory Guidebook, first ed. The European Environmental Agency, Copenhagen, Denmark.

Endresen, Ø., Sørgård, E., et al., 2003. Emission from international sea transportation and environmental impact. Journal of Geophysical Research-Atmospheres 108 (10.1029/2002JD002898).

Flodström, E., 1997. Energy and emission factors for ships in operation. KFB Report 1997:24, The Swedish Transport and Communications Research Board, Stockholm, Sweden, p. 5 .

Georgakaki, A., Sorenson, S.C., 2002. Improving methods of estimating environmental indicators from ocean-going ships. Report to Eurostat, Report no. MEK-ET-2002-05, Technical University of Denmark, Lyngby, Denmark.

Hughes, C., 1996. Ship Performance-Technical, Safety, Environmental and Commercial Aspects, second ed. LLP, London, UK.

Koehler, H.W., 2003. Estimation of $\mathrm{NO}_{x}$ and Other Emissions from Merchant Ocean-going Ships. Shipping World and Shipbuilder July/August 2003, pp. 33-36.

Lloyd's Register Engineering Services, 1995. Marine Exhaust Emissions Research Programme. Lloyd's Register Engineering Services, Croydon, UK, p. 17.

Lloyd's Register of Shipping, 1994. Register of Ships 1994-1995. Lloyd's Register of Shipping, London, UK.

Trozzi, C., Vaccaro, R., 1998. Methodologies for estimating air pollutant emissions from ships. MEET, Deliverable No. 19, Techne report MEET RF98, Rome, Italy.

United States Environmental Protection Agency, 1985. Compilation of Air Pollutant Emission Factors, AP42, fourth ed.

Wall, J.C., Hoekman, S.K., 1984. Fuel Composition Effects on Heavy-Duty Diesel Particulate Emissions. SAE Technical Paper Series, Paper No. 8413664.

\section{Further reading}

Georgakaki, A., Coffey, R., Sorenson, S.C., 2002. Development of a database system for the calculation of indicators of environmental pressure caused by maritime and inland shipping transport. TRENDS Project Final Report to the European Commission-DG TREN, Report No. MEK-ET-2002-04, Technical University of Denmark, Lyngby, Denmark. 